19 Revue d'histoire du XIXe siècle

Société d'histoire de la révolution de 1848 et des

révolutions du XIXe siècle

39 | 2009

Le monde de l'imprimé: des territoires aux acteurs -

Education et politique - Histoires politiques

\title{
Rae Beth GORDON, Dances with Darwin, 1875-1910. Vernacular Modernity in France
}

Farnham, Ashgate, 2009, 311 p. ISBN : 978-0-7546-5243-4. 79 dollars.

Nicole Edelman

\section{QpenEdition}

Édition électronique

URL : http://journals.openedition.org/rh19/3966

DOI : $10.4000 /$ rh19.3966

ISSN : $1777-5329$

Éditeur

La Société de 1848

Édition imprimée

Date de publication : 10 décembre 2009

Pagination : 184-186

ISSN : 1265-1354

Référence électronique

Nicole Edelman, «Rae Beth GORDON, Dances with Darwin, 1875-1910. Vernacular Modernity in France », Revue d'histoire du XIXe siècle [En ligne], 39 | 2009, mis en ligne le 26 mars 2010, consulté le 22 septembre 2020. URL : http://journals.openedition.org/rh19/3966 ; DOI : https://doi.org/10.4000/ rh19.3966

Ce document a été généré automatiquement le 22 septembre 2020.

Tous droits réservés 


\title{
Rae Beth GORDON, Dances with Darwin, 1875-1910. Vernacular Modernity in France
}

Farnham, Ashgate, 2009, 311 p. ISBN : 978-0-7546-5243-4. 79 dollars.

\author{
Nicole Edelman
}

Professeure émérite de littérature française à l'université du Connecticut, Rae Beth Gordon est une des premières, si ce n'est la première, à avoir mis au jour les liens entre littérature, médecine et esthétique en France à la fin du XIXe siècle. Elle a publié plusieurs ouvrages dont Why the French love Jerry Lewis: from Cabaret to Early Cinema en $2001^{1}$. Elle y analysait avec une grande finesse et érudition les influences réciproques entre café-concert, music-hall, cinéma (1896-1912), et médecine. Dans ce nouveau livre, Rae Beth Gordon reprend ce même type d'approche en explorant cette fois les interactions entre les nouvelles notions issues à la fois du darwinisme et des théories neurologiques et psychiatriques et le spectacle populaire français. Elle repère et décrit les nombreux signes de ces liens dans un grand nombre de spectacles. Elle souligne ainsi l'apparition d'une sauvagerie et d'une animalité dans l'esthétique du café-concert et du music-hall parisien. On voit en effet naitre au caf'conc' en 1875 un nouveau genre, celui des "chanteuses épileptiques ». Émilie Bécat et la non moins célèbre Polaire inventent un langage corporel convulsif, composé de mouvements frénétiques, saccadés et mécaniques. Leur danse rappelle la chorée ${ }^{2}$ hystérique ou l'une des phases de la grande hystérie, celle du clownisme, mise en scène sur l'amphithéâtre de La Salpêtrière par le neurologue Jean-Martin Charcot au même moment. On peut aussi lire sous la plume de certains journalistes - c'est l'époque d'une fascination pour l'exotisme et pour les «zoos humains » - que ces chanteuses rappellent par bien des traits les populations « nègres » des contrées colonisées.

2 L'auteure montre combien le « Comique Idiot », autre genre crée au music-hall au XIX siècle et rendu célèbre par Dranem au début $d u \mathrm{XX}^{\mathrm{e}}$ siècle, se réfère aux observations de Darwin lorsqu'il parle de l'idiot comme étant très proche de l'animal dans ses formes d'expressivité. La régression, voire la dégénérescence, est soulignée dans le quadrille 
naturaliste ou le cancan, comparé au véritable «bal des Folles et des Hystériques » qui a lieu tous les ans à La Salpêtrière. Selon certains, elle est aussi présente dans des spectacles de foire ou des cafés-concerts qui présentent des "phénomènes", considérés alors, à la suite de Darwin, comme des chaînons manquants. Enfin, Rae Beth Gordon montre que le «cake-walk», cette danse américaine noire, qui devient un phénomène de société, est reçu et présenté comme la parfaite illustration des théories de l'évolution, de la régression et de la pathologie nerveuse hautement contagieuse. Et nombre de caricatures nous rappellent le profond racisme de la société française.

Rae Beth Gordon analyse en effet des sources multiples: iconographies, musiques, photographies, premiers films sur les chanteuses épileptiques et sur le cake-walk, théories médicales et anthropologiques, romans et essais littéraires qu'elle parvient à tenir ensemble en les croisant et auxquels elle donne sens, renouvelant bien des approches culturelles. Dans un chapitre intitulé « What is Ugly? " elle expose ainsi les théories esthétiques qui enracinent le sens de la beauté dans une origine purement physique : ce qui est beau stimule nos nerfs, ce qui est laid exige des efforts excessifs et crée un dysfonctionnement nerveux. La laideur est donc néfaste pour l'espèce humaine... Rae Beth Gordon souligne alors combien l'enchevêtrement du beau et du laid dans l'art et la littérature fin-de-siècle est un signe essentiel de modernité. Et c'est à la lumière d'un l'éclairage darwinien que dans le dernier chapitre de Dances with Darwin : "Darwin Meets Père Ubu », l'auteure propose une lecture novatrice des Ubu d'Alfred Jarry (Ubu roi en particulier, publié et représenté pour la première fois en 1896). Elle rappelle en effet le grand intérêt de Jarry (1873-1907) pour les questions de l'évolution, pour les animaux préhistoriques (comme en témoigne Ubu cocu ou l'Archéoptérix) ou encore pour les recherches sur le cerveau, sans oublier ses liens avec Bergson qui fut l'un des ses professeurs et... son invention de la " pataphysique ».

Ce livre nous permet donc de porter un nouveau regard sur l'esthétique de cette fin de siècle et de décaler singulièrement la chronologie de la modernité artistique. En effet, comme nous le démontre Dances with Darwin, lorsque les Surréalistes célèbrent en 1928 le cinquantenaire de l'hystérie en proclamant : "L'Art sera convulsif ou ne sera pas", ils sont les héritiers d'une esthétique qui trouve ses racines bien des décennies auparavant dans toutes sortes de ces performances vernaculaires fin-de-siècle.

\section{NOTES}

1. . Rae Beth Gordon, Why the French Love Jerry Lewis: from Cabaret to Early

Cinema, Stanford, Stanford University Press, 2001.

2. . Une sorte de danse de Saint Guy. 